\title{
Role of Total Mesorectal Excision and of Circumferential Resection Margin in Local Recurrence and Survival of Patients with Rectal Carcinoma
}

\author{
Maria Tzardi \\ Department of Pathology, University Hospital, Heraklion, Greece
}

\begin{abstract}
Key Words
Circumferential resection margin - Rectal cancer, histological findings $\cdot$ Rectal cancer, prognostic factors • Rectal carcinoma $\cdot$ Total mesorectal excision
\end{abstract}

\begin{abstract}
Rectal cancer is a common disease with poor prognosis because of local recurrence and metastases. Local recurrence arises mainly as a result of incomplete surgical resection. Evaluation of completeness of the mesorectum provides significant information about prognosis. Total mesorectal excision (TME) has become the surgical treatment of choice for rectal cancer because adopting the principles of TME achieves very low local recurrence rates. The adoption of the TME principles along with the estimation of the circumferential resection margin on the non-peritonealized surface of the resected rectal specimen are the most important predictors of local recurrence.

Copyright $\odot 2007$ S. Karger AG, Basel
\end{abstract}

\section{Introduction}

Rectal cancer is a common disease with poor prognosis because of local recurrence and metastases. A number of prognostic factors have been shown to be related to the survival of patients with rectal cancer. Histological grade and type of tumor, vascular and perineural invasion, TNM stage, tumor-specific molecular features and microsatellite instability have prognostic value in rectal cancer. In recent years, histological findings such as the completeness of the total mesorectal resection and the proximity of the tumor to the circumferential resection margin (CRM) have had a strong prognostic value of both local recurrence and survival.

\section{Total Mesorectal Excision}

Local recurrence arises mainly as a result of incomplete surgical resection. Mesorectal tissue seems to be an ideal substrate for the spreading of tumor. In rectal cancer, local recurrence is present in the absence of distant metastases and this model is different from that in colon cancer in which the local recurrence is often present with distant metastases [1]. Heald and Ryal [2] first proposed that radical surgery for rectal cancer should include complete resection of the mesorectum. The mesorectum consists of the rectum and the surrounding fat tissue with the perirectal lymph nodes and is enveloped by a thin fascia.

In the past, the rate of local recurrence was as high as $20-50 \%[2,3]$. According to different studies, the risk of local recurrence ranged from 2.3 to 28 times in cases with spread of tumor to the mesorectum [4]. Studies showed

\section{KARGER}

Fax +4161306 1234

E-Mail karger@karger.ch

www.karger.com
(C) 2007 S. Karger AG, Basel

0257-2753/07/0251-0051\$23.50/0

Accessible online at:

www.karger.com/ddi
Maria Tzardi

Department of Pathology, University Hospital of Heraklion

GR-71110 Heraklion (Greece)

E-Mail tzardi_maria@yahoo.co.uk 
that the evaluation of completeness of the mesorectum provides significant information about the prognosis.

Macroscopic examination of the mesorectal surface helps us evaluate the quality of the surgical specimen. Mesorectal defects are classified into three categories: (a) complete: mesorectum is intact, smooth with only minor irregularities without defect $>5 \mathrm{~mm}$; (b) moderate: moderate bulk to mesorectum but irregularity of the mesorectal surface; muscularis propria is not visible with the exception of the area of insertion of levator muscles, and (c) incomplete: little bulk to mesorectum with defects down into muscularis propria $[1,5-7]$.

There is also a grading system used to determine the completeness of the mesorectal excision in which grade 1 indicates incomplete resection, grade 2 nearly complete, and grade 3 complete resection [7-9].

Nagtegaal and van Krieken [6] showed that patients with an incomplete mesorectum have a higher risk of recurrence $(36 \%)$ than those with complete mesorectum (20\%). Several studies have proved that total mesorectal excision (TME) has reduced the local recurrence rates. Heald and Ryal [2] showed that after TME the local recurrence rate was reduced from $30-40 \%$ to $5-15 \%$. Arbman et al. [10] have shown that adopting the technique of TME can result in a $20 \%$ improvement in the 4 -year survival rate, and the Norwegian Rectal Cancer Group [11] showed a greater improvement.

Sometimes there is a disagreement between the surgeon and pathologist, or there cannot be certainty about the completeness of the mesorectum. Martling et al. [12] showed that when the surgeon or pathologist were uncertain or there was a disagreement about the completeness of the mesorectum, the risk of recurrence was similar to that of incomplete resection.

In the literature there are studies which focus on the difference of TME between tumors which are located at $\leq 6 \mathrm{~cm}$ from the anal verge and tumors at $>6 \mathrm{~cm}$ from the anal verge. They showed that low rectal tumors have a higher rate of recurrence than the tumors at $>6 \mathrm{~cm}$ and they consider the unresected positive lateral lymph nodes as a possible explanation [13,14]. Only a Japanese group [14] have performed lateral node dissection after en bloc resection of the rectum, the mesorectum with visceral pelvic fascia and the lateral sidewall structures including the pelvic nerve plexuses. They consider that patients with lateral nodal involvement must have a lateral dissection, even if their results are not based on randomized studies.

The position of the tumor in the circumference of the rectum probably has a clinical value. The results from studies focusing on the position of the tumor are contradictory. A study showed that the circumferential position of the tumor had a worse prognosis than others and anteriorly positioned tumors had a significantly higher survival rate [15]. Another study of 401 patients with rectal cancer showed no difference in the rate of recurrence and the survival based on the position of the tumor. The same study showed that anteriorly placed tumors tend to be more advanced and male patients with an anteriorly placed tumor had a higher risk of recurrence than with tumors in another location. The authors consider that the predilection of gender was a result of different surgical treatment [16].

TME has become the surgical treatment of choice for rectal cancer and now there is an accumulation of evidence indicating that surgeons who have adopted the principles of TME can consistently achieve local recurrence rates of $3-10 \%$ and an overall survival rate of up to $80 \%[1,2,5-7,13,17-20]$.

\section{Circumferential Resection Margin}

After the introduction of TME, the CRM on the nonperitonealized surface of the resected rectal specimen is one of the most important predictors of local recurrence. Quirke et al. [21] were the first to show that the radial or CRM is an important factor for local recurrence. The CRM can be involved by the tumor in various ways, such as direct spread, by tumor emboli in veins, lymphatics or lymph nodes or by tumor deposits discontinuous from the main growth [21-23].

The rectum is covered anteriorly by peritoneum and only in the area below the peritoneal reflection is there a risk of the CRM being involved. The posterior area, which continues up to the sigmoid mesocolon, is at risk of being involved by the tumor not only by direct spread but also with metastatic deposits in lymph nodes. The mesorectum is thinner anteriorly than posteriorly and the risk of a positive resection margin is higher for anteriorly located tumors than in posterior ones.

Microscopic tumor nodules can be observed in the mesorectum. Studies have shown that the presence of widespread microscopic nodules in the mesorectum was present in up to $38.7 \%$. In $25.8 \%$ of cases these were detected in the outer part of the mesorectum. Other studies proved that lymph nodes $<5 \mathrm{~mm}$ in diameter are more often involved by the tumor than bigger ones. Such findings pinpoint the importance of TME [24-26]. The pathologist must differentiate the peritonealized from non- 
peritonealized surfaces of the resection. If a tumor is detected on the non-peritonealized surface, adjuvant radiotherapy may be appropriate without the dimensions of the tumor to be considered.

Histological examination of the rectal specimen is based on a method described by Quirke et al. [21]. The lateral resection margin of the fresh surgical specimen must be inked. The surgical specimen is opened apart from the tumor area and $2 \mathrm{~cm}$ below and above it. The specimen is fixed for $48 \mathrm{~h}$. After fixation the specimen is sliced transversely at 3- to 4-mm intervals, looking for continuous spread and/or discontinuous tumor deposits and for involved lymph node at the CRM $[1,5,6,21,23$, 27-29]. The macroscopic CRM is measured with a ruler; the microscopic CRM measurement is done better by using a sheet of graph paper that is photocopied onto a sheet of acetate and cut to size than to using the Vernier scale $[5,23]$. The CRM is divided into two categories: an involved (positive) CRM when the tumor extends to within $1 \mathrm{~mm}$ of the circumferential margin and an uninvolved (negative) CRM when the distance between the tumor and CRM is $>1 \mathrm{~mm}$ [21].

Adam et al. [30] and Quirke et al. [21] showed that involvement of the circumferential margin was detected in $25 \%$ of specimens for which the surgeon thought the resection was potentially curative and in $36 \%$ of all the cases. The frequency of local recurrence was $78 \%$ in patients with tumor involvement of the CRM versus $10 \%$ in patients without involvement.

Wibe et al. [31] reviewed the rates of overall survival, local recurrence and distant metastasis in 686 patients with known circumferential margins (margin $<1 \mathrm{~mm}$ ) after TME in order to determine the prognostic impact. Overall local recurrence rate was $7 \%$. The local recurrence was significantly higher in patients with a positive resection margin (22\%) versus a negative margin (5\%). $40 \%$ of patients with positive margin developed distant metastasis versus $12 \%$ of patients with a negative margin. They concluded that information on the circumferential margin might help in selecting those patients who should receive adjuvant therapy $[31,32]$.

Another study showed that cases with positive CRMs have a $37 \%$ risk of developing distant metastases versus $15 \%$ in cases with margins $>1 \mathrm{~mm}$. The same study showed a lower survival rate, 70 vs. $90 \%$, in the 2 -year follow-up [6].

All the studies in the literature consider a positive CRM to be a distance between tumor and margin of $<1 \mathrm{~mm}$. However, in one study the risk of local recurrence was high at $2 \mathrm{~mm}$. In that study, patients with margins $\leq 2 \mathrm{~mm}$ had a risk of $16 \%$ local recurrence within 2 years after operation, while, on the other hand, patients with margins $>2 \mathrm{~mm}$ had a risk of 5.8\% [28]. Several studies have focused on CRM and have indicated that the frequency of positive CRM varied between 15 and $48 \%$, and the authors consider that is influenced by the type of surgery performed. Several studies also indicated that the frequency of a positive CRM is higher in abdominoperineal resection than in low anterior resection $[21,23,33]$.

The CRM may be involved by the presence of positive lymph nodes. Nagtegaal et al. [20,28] showed that the local recurrence rate in patients with a positive resection margin due to a positive lymph node in the resection was not different from the local recurrence rates in patients with negative margins. Some authors consider that there are two different subgroups in the category of positive CRMs if it is compared with the R classification (residual tumor) $[23,34]$. They consider that there is a group where the tumor extends up to the CRM, corresponding to R1, and a second group where the tumor is observed $\leq 1 \mathrm{~mm}$ to the CRM, corresponding to R0 [23,34]. Studies have shown that there is a prognostic difference between the two subgroups, for example Birbeck et al. [29] and Nagtegaal et al. [28] indicated that the rate of local recurrence was 55 and 33\% respectively for patients with a tumor at the circumferential margin (R1) versus 28 and $8 \%$ respectively in patients with a tumor $\leq 1 \mathrm{~mm}$ from the circumferential margin (R0).

\section{Preoperative Staging}

Preoperative staging is used to determine the need for neoadjuvant therapy and to choose the optimal surgical treatment. For this reason, a number of imaging methods are used, including endorectal ultrasound, computed tomography scan, magnetic resonance imaging and positron emission tomography (PET scan) [19]. Studies indicate that patients with positive CRM may benefit from preoperative radiotherapy and that preoperative radiation therapy reduces the local recurrence rate from 8.2 to $2.4 \%[31,32,35]$. In advanced rectal cancer it is well documented that long-course preoperative therapy and chemoradiotherapy lead to regression of the tumor.

Most of the radiology studies have focused on $\mathrm{T}$ and N stage of rectal cancer rather than on CRMs [19, 35-37]. A few have indicated that high-resolution MRI can be used to determine the status of the circumferential mar$\operatorname{gin}[35,38]$. 


\section{Conclusion}

Surgeons make all efforts to improve the surgical techniques in order to obtain negative CRMs. The pathology report gives information which can help determine factors that contribute to local recurrence and decide postoperative treatment. The elements of the pathology report consist of completeness of mesorectum, the CRM, type and grade of the carcinoma, the number of positive lymph nodes and vascular invasion. The newer MRI techniques may play a role in determining preoperatively mesorectum and the CRM in order to select patients with a high risk of CRM involvement and for those patients preoperative radiochemotherapy is the treatment of choice. PET scanning may have a role in determining locally advanced tumor response to neoadjuvant chemotherapy.

It is now obvious that to obtain a low rate of local recurrence and to improve the overall survival of patients with rectal cancer, we need close collaboration between surgeons, pathologists, radiologists and oncologists.

\section{References}

1 Compton CC: Pathologic prognostic factors in the recurrence of rectal cancer. Clin Colorectal Cancer 2002;2:149-160.

-2 Heald RJ, Ryal RD: Recurrence and survival after total mesorectal excision for rectal cancer. Lancet 1986;i:1479-1482.

-3 Nilsson E, Gregersen NP, Hartvig B: Carcinoma of the colon and rectum. Acta Chir Scand 1984;150:513-516.

4 Wang C, Zhou ZG, Wang Z, Li L, Zheng YC, Zhao GP, Chen DY, Liu WP: Mesorectal spread and micrometastasis of rectal cancer studied with large slice technique and tissue microarray. J Surg Oncol 2005;91:167-172.

5 The Pathological Aspect of Rectal Cancer. The TME Workshop by the Pelican Cancer Foundation, 2002.

6 Nagtegaal ID, van Krieken JHJM: The role of pathologists in the quality control of diagnosis and treatment of rectal cancer - an overview. Eur J Cancer 2002;38:964-972.

7 Quirke P: Training and quality assurance for rectal cancer: 20 years of data is enough. Lancet Oncol 2003;4:695-702.

8 Quirke P: Limitations of existing system of staging for rectal cancer; in Rectal Cancer Surgery: Optimization, Standardization and Documentation. Berlin, Springer, 1997, vol 63, p 8132.

9 Nagtegaal ID: Pathological aspects of rectal carcinoma. Studies from RT + TME trial; $\mathrm{PhD}$ thesis, Nijmegen 2002.

10 Arbman G, Nilsson E, Hallbook O, Siodahl $\mathrm{R}$ : Local recurrence following total mesorectal excision for rectal cancer. Br J Surg 1996; 83:375-379.

11 Norwegian Rectal Cancer Group: Total mesorectal excision in Norway: a national rectal cancer project. Dis Colon Rectum 1999;42: A26.

12 Martling A, Singnomklao T, Holm T, Rutqvist LE, Cedermark B: Prognostic significance of both surgical and pathological assessment of curative resection for rectal cancer. Br J Surg 2004;91:1040-1045.
13 Faerden AE, Naimy N, Wiik P, Reiertsen O, Weyessa S, Tronnes S, Norheim Andersen S, Bakka A: Total mesorectal excision for rectal cancer: difference in outcome for low and high rectal cancer. Dis Colon Rectum 2005; 48:2224-2231.

14 Ueno H, Mochizuki H, Hashiguchi Y, Hase K: Prognostic determinants of patient with lateral nodal involvement by rectal cancer. Ann Surgy 2001;234:190-197.

15 Emslie J, Beart R, Mohiuddin M, Marks G: Use of rectal cancer position as a prognostic indicator. Am Surg 1998;64:958-961.

16 Lee SH, Hernandez de Anda E, Finne CO, Madoff RD, Garcia-Aguila J: The effect of circumferential tumor location in clinical outcomes of rectal cancer patients treated with total mesorectal excision. Dis Colon Rectum 2005;48:2249-2257.

17 Martling AL, Holm T, Rutqvist LE, Moran BJ, Heald RJ, Cedermark B, Stockholm Colorectal Cancer Study Group: Effect of a surgical training programme on outcome of rectal cancer in the County of Stockholm. Basingstoke Bowel Cancer Research Project. Lancet 2000;356:93-96.

18 Nesbakkem A, Nygaard K, Westerheim O, Mala T, Lunde OC: Local recurrence after mesorectal excision for rectal cancer. Eur J Surg Oncol 2002;28:126-134.

19 Balch GC, De Meo A, Guillem JG: Modern management of rectal cancer. World J Gastroenterol 2006;12:3186-3195.

20 Nagtegaal ID, van der Velde CJH, van der Worp E, Kapiteijin E, Quirke P: Macroscopic evaluation of rectal cancer resection specimen: clinical significance of the pathologist in quality control. J Clin Oncol 2002;20: 1729-1734.

21 Quirke P, Durdey P, Dixon MF, Williams NS: Local recurrence of rectal adenocarcinoma due to inadequate surgical resection. Lancet 1986;ii:996-999.
22 Quirke P, Dixon MF: The prediction of local recurrence in rectal adenocarcinoma by histopathological examination. Int J Colorect Dis 1988;3:127-131.

23 Hermanek P, Junginger T: The circumferential resection margin in rectal carcinoma surgery. Tech Coloproctol 2005;9:193-200.

24 Wang Z, Zhou ZG, Wang C, Zhao GP, Chen YD, et al: Microscopic spread of low rectal cancer in regions of mesorectum: pathologic assessment with whole-mount sections. World J Gastroenterol 2004; 10:29492953.

25 Wang C, Zhou ZG, Wang Z, Chen YD, et al: Nodal spread and micrometastasis within mesorectum. World J Gastroenterol 2005;11: 3586-3590.

26 Wang C, Zhou ZG, Wang Z, Zheng Y, et al: Patterns of neoplastic foci and lymph node micrometastasis within mesorectum. Langenbecks Arch Surg 2005;390:312-318.

27 Quirke P, Williams GT: Minimum Dataset for Colorectal Cancer: Histopathology Reports. London, Royal College of Pathologists, 2004.

28 Nagtegaal ID, Maijnen CAM, Kranenbarg EK, van de Velde CJK, van Krieken JHM: Circumferential margin involvement is still an important predictor of local recurrence in rectal carcinoma. Not one millimeter but two millimeters is the limit. Am J Surg Pathol 2002;26:350-357.

29 Birbeck KF, Macklin GP, Tiffin NJ, Parsons W, Dixon MF, Mapstone NP, Abbott CR, Scott N, Finan PJ, Johnston D, Quirke P: Rates of circumferential resection margin involvement vary between surgeons and predict outcomes in rectal cancer surgery. Ann Surgery 2002;235:449-457.

30 Adam IJ, Mohamdee MO, Martin IG: Role of circumferential margin involvement in the local recurrence of rectal cancer. Lancet 1994;344:707-11. 
31 Wibe A, Rendedal PR, Svensson E, Norstein J, Eide TJ, Myrvold HE, Soreide O: Prognostic significance of the circumferential resection margin following total mesorectal excision for rectal cancer. Br J Surg 2002;89: 327-334.

-32 Madoff RD, Sharon L, Dykes, MD: What's new in colon and rectal surgery. J Am Coll Surg 2004;198:91-104.

33 Wibe A, Syse A, Andersen E, Tretli S, Myrvold HE, Soreide O, Norwegian Rectal Cancer Group: Oncological outcomes after total mesorectal excision for cure for cancer lower rectum: anterior vs. abdominoperineal resection. Dis Colon Rectum 2004;47:48-58.
34 Hermanek P, Wittekind C: The pathologist and the residual tumor $(\mathrm{R})$ classification. Pathol Res Pract 1994;190:115-123.

35 Kapiteijn E, Marijnen CA, Nagteggal ID, et al: Preoperative radiotherapy combined with total mesorectal excision for respectable rectal cancer. N Engl J Med 2001;345: 638-646.

36 Oberholzen K, Junginger T, Kreitner KF, Krummenauer F, Simiantonaki N, Trouet S, Thelen M: Local staging of rectal carcinoma and assessment of the circumferential resection margin with high-resolution MRI using an integrated parallel acquisition technique. J Magn Reson Imaging 2005;22:101-108.
37 Mathur P, Smith JJ, Ramsey C, Owen M, Thorpe A, Karim S, Burke C, Ramesh S, Dawson PM: Comparison of CT and MRI in the preoperative staging of rectal adenocarcinoma and prediction of circumferential resection margin involvement by MRI. Colorectal Dis 2003;5:396-401.

38 Beets-Tan RGH, Beets GL: Rectal cancer: review with emphasis on MRI. Radiology 2004;232:335-346.

\section{Announcement}

\section{1st Pan American Congress of Digestive Diseases 'Global Challenges in Gastroenterology from the End of the World'}

Santiago, Chile, November 11-14, 2008 